\title{
Neurologic and Immunologic Complications of COVID-19: Potential Long-Term Risk Factors for Alzheimer's Disease
}

\author{
Jack C. Lennon ${ }^{\mathrm{a}, \mathrm{b}, *}$ \\ ${ }^{a}$ Department of Psychology, Adler University, Chicago, IL, USA \\ ${ }^{\mathrm{b}}$ Department of Neurological Sciences, Rush University Medical Center, Chicago, IL, USA
}

Accepted 23 May 2020

\begin{abstract}
The COVID-19 pandemic has been met with studies on risk factors, characteristics, and clinical course. Among these characteristics are neurologic symptoms, which may provide improved insight into the mechanisms of this novel virus and the brain's susceptibility to infectious diseases. This article aims to discuss 1) findings related to neurologic complications, 2) how they connect to and are bidirectionally impacted by bioimmunology, 3) how this combination of biological mechanisms impact and are impacted by psychosocial stressors, and 4) the importance of considering potential neurodegenerative consequences of COVID-19. Longitudinal studies on neuropathology and cognition are critical to avoiding premature conclusions related to long-term neurologic effects.
\end{abstract}

Keywords: Alzheimer's disease, coronavirus disease 2019 (COVID-19), immunology, neurobiology, stress

Much will be discovered over time regarding long-term outcomes of coronavirus disease 2019 (COVID-19) exposure. While focus is primarily on pulmonary function, extrapulmonary dysfunction such as neurologic manifestations are gaining attention as we continue to witness otherwise healthy individuals being impacted. While older adults are still considered at increased risk of severe and potentially fatal consequences of the pandemic due to comorbidities and otherwise compromised immune function, there should be elevated concern related to

${ }^{*}$ Correspondence to: Jack C. Lennon, MA, 17 N Dearborn St, Chicago, IL 60602, USA. E-mail: jack_lennon@ rush.edu;

ORCID iD: 0000-0002-8490-2807 long-term neurologic effects of COVID-19 exposure and recovery for both young and older populations. The question, then, is not whether or not these are age-related risk factors for COVID-19 or health concerns that will persist upon COVID-19 remission, but whether or not patients will be at greater risk for neurodegenerative processes, specifically Alzheimer's disease $(\mathrm{AD})$, during and subsequent to recovery.

Central nervous system (CNS) manifestations are arguably most concerning as it relates to populations at risk for $\mathrm{AD}$, particularly those who are treated and subsequently recover. While there is still much to learn about COVID-19's effects on the brain, it is worth considering how this may impact one's risk of $\mathrm{AD}$ given the overlap in noted neurologic and immunologic alterations. Mao and colleagues 
engaged in a retrospective, observational case series that focuses on neurologic manifestations of hospitalized patients with COVID-19 [1]. Approximately $36.4 \%$ of the sample of 214 patients presented with neurologic manifestations, with severe cases being more likely to experience these symptoms than nonsevere cases $(p=0.02)$. This has been the starting point of evidence of COVID-19 ramifications outside of the respiratory and cardiovascular systems.

Some of the earliest neurologic findings were in those experiencing COVID-19-related anosmia and dysgeusia [2]. Important to this equation is that COVID-19 may prove to be a risk factor for future neurodegenerative disorders, beyond that which would be expected in the context of other comorbidities and genetic predispositions. Anosmia and the biological processes resulting in this symptom contribute to grey matter loss in cortical regions [3], which is similar to where pathognomonic amyloid plaques are often discovered [4]. Olfactory dysfunction has also been found to be associated with the graduation from mild cognitive impairment (MCI) to $\mathrm{AD}$, serving as a potential identifier for preclinical stages [5]. Our concern with a rapid increase in $\mathrm{AD}$ patients due to the sheer size of the Baby Boomer generation may be extended if AD pathogenesis is altered or increased in progression rate by a novel virus. The median duration of viral shedding (20 days) for survivors [6] does not necessarily imply that neurologic damage is also transient, which is likely dependent on infection course, treatment, and recovery. Pleasure and colleagues [7] reported that stroke and alterations of consciousness often occur not only in the context of severe acute respiratory syndrome but also later in the recovery process. However, this article also suggested that COVID-19 may be drawing closer attention to underlying conditions and risk factors rather than serving as a risk factor in itself. While this could be argued based on temporal association of events, those who move on to return home at their perceived physical baselines may not be facing the same trajectory moving forward.

Premature immunosenescence plays a putative role in $\mathrm{AD}$ pathogenesis, such that lymphocytic changes in distribution and levels may impact $A D$ risk [8]. This is in alignment with findings in COVID-19-positive patients in Wuhan [1]. Further, blood urea nitrogen and creatinine kinase levels in severe COVID-19 cases have been observed as significantly altered [1], consistent with studies on blood-cerebrospinal fluid barrier (BCSFB) function and neurodegeneration that suggest a seem- ingly important alteration in BCSFB permeability in those with $\mathrm{AD}$ [9]. Muscular injuries, irrespective of COVID-19 severity, have been highlighted as presenting with elevated neutrophil counts compared to those without injury [1]. These heterogeneous neutrophils play a critical role in immune response and inflammation due to threat to maintain homeostasis, but when this inflammation is due to injury, neutrophils can result in substantial tissue damage, acquire a toxic phenotype within the CNS, and introduce new molecules that can impact AD risk [10].

It has become clear that many age-related conditions are found among those testing positive for COVID-19, though some of these are also related to lifestyle and family history. For example, Zhou and colleagues [6] found that hypertension, diabetes, and coronary artery disease were the most common comorbidities in a sample of 191 COVID19-positive patients (median [IQR] age $=56.0$ [46.0 to 67.0] years). Systolic hypertension in midlife, rather than only late life, is associated with $18 \%$ and $25 \%$ increased risk of $\mathrm{AD}$, respectively [11]. COVID19 deaths have also been associated with an odds ratio of 18.42 when d-dimer levels are greater than $1 \mu \mathrm{g} / \mathrm{mL}$ [6], which is a biomarker involved in $\mathrm{AD}$ that complicates diabetes, particularly in the context of carotid artery plaques [12]. Diabetes and obesity, which can result in cardiovascular events and diseases, are also modifiable risk factors of $\mathrm{AD}$ that can alter blood-brain barrier permeability of immunerelated cells and, thus, impact inflammation [13]. These cardiovascular risk factors are directly related to cerebrovascular consequences, such as hypoperfusion, a symptom strongly associated with MCI and AD [14]. Plasma exchange and albumin for AD patients with hypoperfusion, for example, has been shown to improve cognitive deficits and initiate cerebrospinal fluid (CSF) amyloid- $\beta$ (A $\beta$ ) [15]. These albumin levels are a concern for COVID-19 patients as well, such that nephritis and other complications could be similarly treated [16]. Family history also extends to $A D$, such that $A \beta$-positive individuals are not only more likely to have a family history of dementia but are also more likely to carry at least one apolipoprotein $\mathrm{E}(A P O E) \varepsilon 4$ allele [17]. Thus, it may be clinically inappropriate to view comorbidities as a function of age but, instead, family history because it encompasses a broader view of the situation at-hand.

Behavioral and psychological symptoms of dementia (BPSD), found in approximately $90 \%$ of $\mathrm{AD}$ patients [18], cannot be neglected in the context of the COVID-19 pandemic. Frontline healthcare 
workers are at increased risk for anxiety, depression, and stress, with some concern related to posttraumatic stress symptomatology [19]. Along with the clinical phenotypes that define BPSD, the recursive effects over time are arguably more important to pathogenesis than mere presence. The serotonergic alterations that both result in and are altered by BPSD are critical components of disease trajectory. For example, affective symptoms are found to increase the risk of premature mortality, particularly as a function of time, attenuated most strongly by existing health conditions [20]. Therefore, it is reasonable to suspect that a highly stressful and uncertain situation could significantly impact disease course in not only those at risk, but those who were not initially at risk for $\mathrm{AD}$. It is important to consider the bidirectional nature of biological mechanisms related to psychosocial stress responses. Evidence is not lacking in terms of purported mechanistic relationships between stress- and trauma-related events and dysregulation of immune response to inflammation [21]. The observed microglial dysregulation during stressful events is that which is implicated in $\mathrm{AD}$ pathogenesis due to the preferential expression of microglia by identified risk genes [22]. Acute necrotizing encephalopathy, a potential complication of viral infections, can further impact the breakdown of blood-brain-barrier functionality and the start of cytokine storms [23]. This immune response is potentially why convalescent plasma has proven to be a viable treatment option for COVID-19 [24, 25]. Stroke is another known adverse event associated with COVID-19, yet this relationship is not fully understood at present [26]. Thus, it should not go unnoticed that AD patients are at a greater risk of hemorrhagic stroke than controls [27] and that cardiorespiratory state impacts this stroke risk [28].

Future research, tailored to the brain, would allow us to better understand COVID-19 over the course of symptoms and in the context of viral shedding, as well as the potential risks it may pose in the future. For example, $A \beta$ positron emission tomography (PET) for those without cognitive impairment or MCI, tau PET using ${ }^{18}$ F-RO-948 for those with cognitive deficits [29], and CSF tau [30] should be collected along with $A P O E$ genotyping. Regions of interest should be created to ensure that results approximate the original development of the Braak system for tau pathology [31]. These variables are commonly collected in AD studies, particularly within the National Alzheimer's Coordinating Center (NACC), and are interrelated to a degree that warrants ongoing collec- tion. Neuropsychological measures should be utilized to gauge cognitive performance both at baseline and over time in relation to these noted $\mathrm{AD}$ biomarkers [32].

The monitoring of COVID-19 patients for both clinical and research purposes is of utmost importance. It is likely that some of the complications, depending on age and medical history, will require substantial follow-up following viral shedding. There will also be behavioral and psychological consequences that should be carefully considered even when not spontaneously endorsed by patients. Thus, research could be conducted in the context of routine clinical work to avoid other patient-specific barriers related to travel and time. Given the extent of ramifications following the spread of COVID-19 across the globe, it would behoove both the public and scientific community to ensure that we understand the connections between future AD risk and COVID-19. This information would arguably prove invaluable should another pandemic arise or, even with COVID-19, a new spike in the coming months.

There are meaningful connections between the neurologic and immunologic complications of COVID-19 and those that impact neurodegeneration and AD pathogenesis. It would be a missed opportunity for neurologists to move into position to accept neurologic presentations under the assumption that a history of COVID-19 does not have a lasting impact. Whether or not this question is clinically meaningful is currently premature-considering the importance of ongoing research that follows these individuals over time is both apropos and a scientific obligation. Premature conclusions can logically affect our understanding of neurodegenerative processes, such that meaningful factors are lost in translation or ignored altogether for the sake of taking a presentation at facevalue. COVID-19 may offer unique insights into $A D$ neuropathology through the brain's susceptibility to certain viruses and other infectious agents.

\section{Human and animal rights in informed consent}

In this article, the cited articles contain studies with human and/or animal work approved by institutional review boards prior to publication.

\section{ACKNOWLEDGMENTS}

Jack C. Lennon is a Board Member of Journal of Alzheimer's Disease. Jack C. Lennon is supported by the Alfred Adler Scholarship. 


\section{CONFLICT OF INTEREST}

The author discloses no conflicts of interest, competing interests, or potential financial interests.

\section{REFERENCES}

[1] Mao L, Jin H, Wang M, Hu Y, Chen S, He Q, Chang J, Hong C, Zhou Y, Wang D, Miao X, Li Y, Hu B (2020) Neurologic manifestations of hospitalized patients with coronavirus disease 2019 in Wuhan, China. JAMA Neurol, doi: 10.1001/jamaneurol.2020.1127

[2] Guan WJ, Ni ZY, Hu Y, Liang WH, Ou CQ, He JX, Liu L, Shan H, Lei CL, Hui DSC, Du B, Li LJ, Zeng G, Yuen KY, Chen RC, Tang CL, Wang T, Chen PY, Xiang J, Li SY, Wang JL, Liang ZJ, Peng YX, Wei L, Liu Y, Hu YH, Peng P, Wang JM, Liu JY, Chen Z, Li G, Zheng ZJ, Qiu SQ, Luo J, Ye CJ, Zhu SY, Zhong NS; China Medical Treatment Expert Group for Covid-19 (2020) Clinical characteristics of coronavirus disease 2019 in China. N Engl J Med 382, 1708-1720.

[3] Sasaki S (2019) Synergistic effects of Alzheimer's disease and parkinsonism on olfactory impairment. J Alzheimers Dis Parkinsonism 9, 460.

[4] Hiscox LV, Johnson CL, McGarry MDJ, Marshall H, Ritchie CW, van Beek EJR, Roberts N, Starr JM (2020) Mechanical property alterations across the cerebral cortex due to Alzheimer's disease. Brain Commun 2, fcz049.

[5] Kotecha AM, Corrêa ADC, Fisher KM, Rushworth JV (2018) Olfactory dysfunction as a global biomarker for sniffing out Alzheimer's disease: A meta-analysis. Biosensors (Basel) 8, 41.

[6] Zhou F, Yu T, Du R, Fan G, Liu Y, Liu Z, Xiang J, Wang Y, Song B, Gu X, Guan L, Wei Y, Li H, Wu X, Xu J, Tu S, Zhang Y, Chen H, Cao B (2020) Clinical course and risk factors for mortality of adult inpatients with COVID-19 in Wuhan, China: A retrospective cohort study. Lancet 395, 1054-1062.

[7] Pleasure SJ, Green AJ, Josephson A (2020) The spectrum of neurologic disease in the severe acute respiratory syndrome coronavirus 2 pandemic infection: Neurologists move to the frontlines. JAMA Neurol, doi: 10.1001/jamaneurol.2020.1065.

[8] Richartz-Salzburger E, Batra A, Stransky E, Laske C, Köhler N, Bartels M, Buchkremer G, Schott K (2007) Altered lymphocyte distribution in Alzheimer's disease. $J$ Psychiatr Res 41, 174-178.

[9] Johanson CE, Stopa EG, Daiello L, de la Monte S, Keane M, Ott BR (2018) Disrupted blood-CSF barrier to urea and creatinine in mild cognitive impairment and Alzheimer's disease. J Alzheimers Dis Parkinsonism 8, 435.

[10] Rossi B, Contantin G, Zenaro E (2020) The emerging role of neutrophils in neurodegeneration. Immunobiology 225, 151865 .

[11] Lennon MJ, Makkar SR, Crawford JD, Sachdev PS (2019) Midlife hypertension and Alzheimer's disease: A systematic review and meta-analysis. J Alzheimers Dis 71, 307-316.

[12] Wang J, Huang R, Tian S, Lin H, Guo D, An K, Wang $S$ (2019) Elevated plasma level of D-dimer predicts the high risk of early cognitive impairment in type 2 diabetic patients as carotid artery plaques become vulnerable or get aggravated. Curr Alzheimer Res 16, 396-404.

[13] Pugazhenthi S, Qin L, Reddy PH (2017) Common neurodegenerative pathways in obesity, diabetes, and Alzheimer's disease. Biochem Biophys Acta Mol Basis Dis 1863, 10371045.

[14] de la Torre JC (2016) Cerebral perfusion enhancing interventions: A new strategy for the prevention of Alzheimer dementia. Brain Pathol 26, 618-631.

[15] Boada M, López O, Núñez L, Szczepiorkowski ZM, Torres M, Grifols C, Páez A (2019) Plasma exchange for Alzheimer's disease management by albumin replacement (AMBAR) trial: Study design and progress. Alzheimers Dement 5, 61-69.

[16] Gross O, Moerer O, Weber M, Huber TB, Scheithauer S (2020) COVID-19-associated nephritis: Early warning for disease severity and complications? Lancet 395, e87-e88.

[17] Sperling RA, Donohue MC, Raman R, Sun CK, Yaari R, Holdridge K, Siemers E, Johnson KA, Aisen PS; A4 Study Team (2020) Association of factors with elevated amyloid burden in clinically normal older individuals. JAMA Neurol, doi: 10.1001/jamaneurol.2020.0387

[18] Chakraborty S, Lennon JC, Malkaram, SA, Zeng Y, Fisher DW, Dong H (2019) Serotonergic system, cognition, and BPSD in Alzheimer's disease. Neurosci Lett 704, 36-44.

[19] Tan BYQ, Chew NWS, Lee GKH, Jing M, Goh Y, Yeo LLL, Zhang K, Chin HK, Ahmad A, Khan FA, Shanmugam GN, Chan BPL, Sunny S, Chandra B, Ong JJY, Paliwal PR, Wong LYH, Sagayanathan R, Chen JT, Ying Ng AY, Teoh HL, Ho CS, Ho RC, Sharma VK (2020) Psychological impact of the COVID-19 pandemic on health care workers in Singapore. Ann Intern Med, doi: 10.7326/M20-1083.

[20] Archer G, Kuh D, Hotopf M, Stafford M, Richards M (2020) Association between lifetime affective symptoms and premature mortality. JAMA Psychiatry, doi: 10.1001/jamapsychiatry.2020.0316.

[21] Ray A, Gulati K, Rai N (2017) Stress, anxiety, and immunomodulation: A pharmacological analysis. In Vitamins and Hormones (Vol. 103). Academic Press, pp. 1-25.

[22] Hansen DV, Hanson JE, Sheng M (2017) Microglia in Alzheimer's disease. J Cell Biol 217, 459-472.

[23] Poyiadji N, Shahin G, Noujaim D, Stone M, Patel S, Griffith B (2020) COVID-19-associated acute hemorrhagic necrotizing encephalopathy: CT and MRI features. Radiology, doi: 10.1148/radiol.2020201187

[24] Rojas M, Rodríguez Y, Monsalve DM, Acosta-Ampudia Y, Camacho B, Gallo JE, Rojas-Villarraga A, Ramírez-Santana C, Díaz-Coronado JC, Manrique R, Mantilla RD, Shoenfeld Y, Anaya JM (2020) Convalescent plasma in Covid19: Possible mechanisms of action. Autoimmun Rev 19, 102554

[25] Duan K, Liu B, Li C, Zhang H, Yu T, Qu J, Zhou M, Chen L, Meng S, Hu Y, Peng C, Yuan M, Huang J, Wang Z, Yu J, Gao X, Wang D, Yu X, Li L, Zhang J, Wu X, Li B, Xu Y, Chen W, Peng Y, Hu Y, Lin L, Liu X, Huang S, Zhou Z, Zhang L, Wang Y, Zhang Z, Deng K, Xia Z, Gong Q, Zhang W, Zheng X, Liu Y, Yang H, Zhou D, Yu D, Hou J, Shi Z, Chen S, Chen Z, Zhang X, Yang X (2020) Effectiveness of convalescent plasma therapy in severe COVID-19 patients. Proc Natl Acad Sci U S A 117, 9490-9496.

[26] Markus HS, Brainin M (2020) COVID-19 and stroke - A global World Stroke Organization perspective. Int J Stroke 15, 361-364.

[27] Waziry R, Chibnik LB, Bos D, Ikram MK, Hofman A (2020) Risk of hemorrhagic and ischemic stroke in patients with Alzheimer disease: A synthesis of the literature. Neurology 94, 265-272.

[28] Wang Y, Li F, Cheng Y, Gu L, Xie Z (2020) Cardiorespiratory fitness as a quantitative predictor of the risk 
of stroke: A dose-response meta-analysis. J Neurol 267, 491-501.

[29] Leuzy A, Smith R, Ossenkoppele R, Santillo A, Borroni E, Klein G, Ohlsson T, Jögi J, Palmqvist S, MattssonCarlgren N, Strandberg O, Stomrud E, Hansson O (2020) Diagnostic performance of RO948 F 18 tau positron emission tomography in the differentiation of Alzheimer disease from other neurodegenerative disorders. JAMA Neurol, doi: 10.1001/jamaneurol.2020.0989.

[30] Hohman TJ, Dumitrescu L, Barnes LL, Thambisetty M, Beecham G, Kunkle B, Gifford KA, Bush WS, Chibnik LB, Mukherjee S, De Jager PL, Kukull W, Crane PK, Resnick SM, Keene CD, Montine TJ, Schellenberg GD, Haines JL, Zetterberg H, Blennow K, Larson EB, Johnson SC, Albert
M, Bennett DA, Schneider JA, Jefferson AL; Alzheimer's Disease Genetics Consortium and the Alzheimer's Disease Neuroimaging Initiative (2018) Sex-specific association of apolipoprotein E with cerebrospinal fluid levels of tau. JAMA Neurol 75, 989-998.

[31] Braak H, Braak E (1995) Neuropathological stageing of Alzheimer-related changes. Acta Neuropathol 82, 239-259.

[32] Weintraub S, Salmon D, Mercaldo N, Ferris S, GraffRadford NR, Chui H, Cummings J, DeCarli C, Foster NL, Galasko D, Peskind E, Dietrich W, Beekly DL, Kukull WA, Morris JC (2009) The Alzheimer's Disease Centers' Uniform Data Set (UDS): The neuropsychological test battery. Alzheimer Dis Assoc Disord 23, 91-101. 